\title{
Preparation of Electrochemical Sensor Based on Magnetic Graphene Nanocomposite for Determination of Dopamine
}

\author{
Weiwei Wang ${ }^{*}$, Fan Wei, Baiping Han \\ School of Physics and New Energy, Xuzhou University of Technology, Xuzhou, Jiangsu 221018, \\ People's Republic of China \\ *E-mail: wwwang@xzit.edu.cn, weifanqi@mail.ustc.edu.cn, baiping09290@163.com
}

Received: 7 November 2021 / Accepted: 7 December 2021 / Published: 5 January 2022

\begin{abstract}
This work was focused on the preparation of an electrochemical sensor based on magnetic graphene nanocomposite for the determination of dopamine (DA) in human plasma samples. The electrodeposition method was used for the synthesis of magnetic graphene nanocomposite based on $\mathrm{Fe}-$ $\mathrm{Ni}$ bimetal oxides $\left(\mathrm{Fe}_{2} \mathrm{O}_{3}-\mathrm{NiO}\right)$ and graphene oxide $(\mathrm{GO})$ on a glassy carbon electrode (GCE). $\mathrm{Fe}_{2} \mathrm{O}_{3}-$ NiO@GO/GCE using XRD and SEM confirmed the simultaneous electrodeposition of Fe-Ni bimetal oxide nanoparticles in the spherical-shaped 2D wrinkled stack of ultra-thin GO nanosheets without any aggregation. Electrochemical analyses using DPV and amperometry techniques showed the good electrocatalytic activity, stability, and selectivity of $\mathrm{Fe}_{2} \mathrm{O}_{3}-\mathrm{NiO} @ \mathrm{GO} / \mathrm{GCE}$ towards the oxidation of DA with rapid electron transfer and mass transport. Furthermore, the sensitivity and detection limit of magnetic graphene nanocomposite sensors were obtained at $0.16812 \mu \mathrm{A} / \mu \mathrm{M}$ and $0.005 \mu \mathrm{M}$, respectively, which were compared with the other reported DA electrochemical sensors and the results indicated comparable detection limit values and broader linear range of $\mathrm{Fe}_{2} \mathrm{O}_{3}-\mathrm{NiO} @ \mathrm{GO} / \mathrm{GCE}$ for the determination of DA. The practical capability of $\mathrm{Fe}_{2} \mathrm{O}_{3}-\mathrm{NiO} @ \mathrm{GO} / \mathrm{GCE}$ for the determination of DA was investigated in prepared real samples of human blood serum of six patients aged 55 to 70 years who were administered an intropin injection. Results showed that there was good agreement between the amperometry and ELISA measurements, and the obtained RSD ranged from $3.08 \%$ to $4.36 \%$ illustrated the acceptable accuracy of both techniques, especially $\mathrm{Fe}_{2} \mathrm{O}_{3}-\mathrm{NiO} @ \mathrm{GO} / \mathrm{GCE}$ as a reliable and accurate electrochemical DA sensor in clinical and pharmaceutical analyses.
\end{abstract}

Keywords: Dopamine; Magnetic graphene nanocomposite; Fe-Ni bimetal oxides; Graphene oxide; Amperometry

\section{FULL TEXT}

(C) 2022 The Authors. Published by ESG (www.electrochemsci.org). This article is an open access article distributed under the terms and conditions of the Creative Commons Attribution license (http://creativecommons.org/licenses/by/4.0/). 